\title{
LO AUTOBIOGRÁFICO EN MAZURCA PARA DOS MUERTOS, DE CAMILO JOSÉ CELA \\ Dieudonné Mendogo Minsongui
}

\author{
Universidad de Yaoundé (Camerún)
}

Mazurca para dos muertos ¿intento de reconstitución autobiográfica e histórica?

Philippe Lejeune (1975: 3) es el crítico que ha dedicado una especial atención al tema de autobiografía en una obra considerada hoy día como clásica, Le pacte autobiographique. Define la autobiografía del siguiente modo: «Récit rétrospectif en prose qu'une personne réelle fait de sa propre existence lorsqu'elle met l'accent sur sa vie individuelle en particulier sur l'histoire de sa personnalité». En la definición — sigue- entran en juego cuatro elementos diferentes:

1. Forma de lenguaje:

a) Relato.

b) En prosa.

2. Tema tratado: vida individual o historia de una personalidad.

3. Situación del autor: identidad del autor (persona real) y del narrador. 


\title{
4. Posición del narrador:
}

a) Identidad del narrador y del personaje principal.

b) Perspectiva retrospectiva del relato 1 .

¿Mazurca para dos muertos, de Camilo José Cela, cumple con cada una de las cuatro categorías precedentes?

Nuestro objetivo consistirá en intentar dar respuestas a esta pregunta.

Al escribir Mazurca para dos muertos, Camilo José Cela afirma haberse inspirado en un suceso real que había pasado en su familia y del que tenía conocimiento:

\begin{abstract}
Aunque no quiere hablar de "Mazurca para dos muertos", dice que el punto de arranque fue "un suceso en cierto modo real del que tenía conocimiento y que había pasado en mi familia. Más o menos va diluido en la novela, porque claro, yo parto siempre de un punto de la realidad que pasando por la cabeza del escritor y saliendo, haciendo así, por su mano derecha es lo que se llama novela. Siempre hay un punto de realidad, en todo, incluso en las novelas más abstractas que puedan parecer, porque en definitiva, todas las novelas son autobiográficas, en una clasificación determinada y en un tanto por cien de autobiografía inmediata o no inmediata variable. Como comprenderás, yo no maté a mi madre a puñaladas. Pero que en algún momento tú partes de vivencias personales, no hay la menor duda. Eso es lo que diferencia, problablemente, al novelista del que no lo es» ${ }^{2}$.
\end{abstract}

En el mismo sentido, a una pregunta que le hacía Francisco López (1986: 99) a propósito del final de la novela, Camilo José Cela respondía:

"- Lo que se cuenta ahí, de los perros, lo hizo la familia mía con uno que había matado a un falangista de Carballino que mató a uno de los nuestros..."

En cuanto al desarrollo de nuestro tema, vamos a considerar a continuación tres niveles de aproximación: el primero es la evocación de algunos datos biográficos relacionados más o menos con la propia biografía de Camilo José Cela (el lugar de nacimiento, las constantes alusiones al cumpleaños, la estancia venezolana...); el segundo será la afi-

1 Cf. José Romera (1981: 18).

2 «Cela: He disfrutado como un loco escribiendo Mazurca para dos muertos». Publica su primera novela después de 10 años. El País, 8 de octubre de 1983, 25. 
ción a la literatura, una de las obsesiones de Camilo José Cela; y el tercero, por fin, se referirá a la guerra civil española en la que Camilo José Cela participó durante sus años juveniles.

Uno de los hechos que llama la atención en Mazurca para dos muertos, y que dificulta no sólo la lectura de novela, sino también su comprensión, será la existencia de varias voces narrativas. A pesar de la multiplicidad de estas voces y sin querer establecer relaciones entre el autor de la novela y los personajes, conviene reconocer que algunos datos referentes a la vida de Camilo José Cela se dan a conocer a lo largo del relato a partir de ciertas voces narrativas que podríamos considerar como voces centrales:

La primera es la de Robín Lebozán Castro de Cela, de quien sabemos está escribiendo una novela autobiográfica sobre su infancia y sobre los acontecimientos que constituyen el núcleo de la historia, novela que se nos ofrece fragmentada en la Mazurca confirmando el propio texto de la novela de Camilo José Cela. (Aspecto que desarrollaremos después: la afición a la literatura.)

La segunda voz narrativa puede identificarse con la de su propio Camilo, del clan de los Moranes, quien con Robin Lebozán y Raimundo el de los Casandulfes forma el terceto de jovenes protagonistas centrales de la novela:

«... Marcos Albite y Moncho se fueron a Puxedo, a casa de las Laurentinas, y Robín Lebozán y yo nos llegamos a Cela, a visitar a mis parientes Venceas» (pág. 49).

«Raimundo el de los Casandulfes y yo vimos a nuestra prima Ramona paseando entre los árboles...» (pág. 119).

Se trata del mismo personaje al que, una vez que estalla la guerra civil, se conocerá como el «artillero Camilo» y el que años más tarde -no sabemos exactamente cuántos-- recibirá de los restantes personajes, especialmente del tullido Marco Albite y la viuda Ádega, tratamiento de usted o de «don Camilo», expresándose así un antes y después de la guerra civil, pero también el distanciamiento que, pese al parentesco, impone la nueva condición social del ex artillero, que ahora viste como un señor y lleva «corbata de seda»: que Catuxa no cuenta demasiado, no cuenta casi nada. 
A mí me pareció que aquel era un buen momento.

-Lo mejor sería que nos tuteáramos, antes de la guerra nos tuteábamos, tú también eres un Guxinde como yo.

-Sí, eso sí, pero yo soy un Guxinde pobre, un Guxinde que no vale nada...» (pág. 116).

El mismo Marcos Albite, a quien acabamos de evocar, le hace un «San Camilo» para que se lo lleve de recuerdo. La alusión a este «San Camilo» es una constante a lo largo de la novela:

- ¿Quiere que le haga un San Camilo y se lo lleva de recuerdo?» (pág. 37).

- «Le voy a hacer un San Camilo de arde carallo, la gente se va a quedar de un aire con el San Camilo» (pág. 48).

- «Voy a apuntar en un papel que tengo que pedir más farias a mis primos de La Coruña para regalarle a Marcos Albite, he de corresponder al San Camilo de palo, lo más probable es que sea una obra de arte» (pág. 54).

- «Te tengo casi acabado el santo, es un San Camilo, de siete estralos, ya verás, la semana que viene te lo doy, sólo me falta arrimarle un poco de lija» (p. 117).

- «Marcos Albite está contento porque terminó el San Camilo.

- ¿Quieres ver tan San Camilo? Ya lo terminé, no es porque yo lo diga pero es el San Camilo mejor del mundo, dice que tiene cara de papón, bueno, tú sabes que esa es la cara que se les pone a los santos cuando van a romper a hacer milagros, ¿quieres que llame a Ceferino Furelo para que lo bendiga?

-Bueno, siempre será mejor.

El San Camilo de palo que me hizo Marcos Albite está muy bien, tiene cara de tonto pero a lo mejor es que es así, lo más probable es que sirva para hacer milagros.

-Muchas gracias, Marcos, es muy bonito.

$-¿$ De veras que te gusta?

-Sí, me gusta mucho» (p. 142).

_ «El San Camilo de palo que me hizo Marcos Albite es el mejor del mundo, tiene cara de tonto pero está muy bien, da gusto verlo» (p. 194).

Con todo, el personaje central, desde el punto de vista de la fábula, no de la historia, parece ser don Camilo, quien regresa a las tierras natales para resucitar la memoria y reconstruir, con ayuda del texto de Robin Lebozán y de innumerables testimonios directos, los aconteci- 
mientos claves de su juventud que presentaría algunos problemas de identificación. El texto parece invitar a la fusión con la persona del escritor, es decir, de Camilo José Cela, y en este sentido se dan pistas autobiográficas muy significativas. Ambos tienen la misma edad y han nacido en Padrón; ambos han visitado Venezuela en las misma fechas:

«... muchos piensan que lo mataron en el monte hacia 1950 o 51 en una emboscada que les tendió la guardia civil pero no es verdad, yo estuve con él en Tucupita, capital del territorio Delta amaruco, Venezuela, en 1953...» (pp. 184-195).

Además, algunos detalles de la vida familiar de «don Camilo» se encuentran en La Rosa, la primera entrega de la autobiografía de Camilo José Cela. El narrador habla de «mi tío Claudio Montenegro» y de mi «pariente el santo Fernández», al igual que el Cela de La Rosa:

«Mi tío Claudio Montenegro es un gran caballero medieval, con la cabeza llena de ideas extrañas...»

«-Mi parentesco con el beato Fray Jacobo Fernández es claro. Fue hermano de Rosa, la abuela de mi padre, venida al mundo el 18 de abril de 1810. A Fray Juan Jacobo lo martirizaron el 7 de julio de 1860, en Damasco".

«Los Moranes más puros nos caracterizamos por tener cara de caballo y los dientes separados...» ${ }^{3}$.

Notamos así que algunos datos biográficos de Camilo José Cela se aproximan a los de Camilo, el artillero de Mazurca para dos muertos. Estamos, pues, ante una reconstrucción biográfica fundida a otra de ficción. Camilo José Cela recupera en la novela no sólo la imagen del joven que fue en la aldea gallega, sino también la imagen probable del que hubiera podido ser.

En segundo lugar, conviene detenerse en otro aspecto: la afición a la literatura. Es un tema en el que ha insistido José Romera (1984) en un estudio pormenorizado, del que nosotros nos contentaremos con reproducir algunas de sus conclusiones aquí.

La literatura es una de las grandes obsesiones de Camilo José Cela, y como creador de una realidad, aunque en ficción, va a describir las aficiones literarias de sus personajes a través de los cuales podremos conocer mejor su personalidad.

3 Camilo José Cela, La Rosa. Barcelona: Destino, 1959 (volumen 532): 22, 27, 29 y 30. 
En Mazurca para dos muertos, novela retablo en la que intervienen numerosos personajes - muy en la línea de La Colmena-, debido al medio rural poco propiciador de la cultura y al espacio cronológico - prolegómenos y guerra civil-, son muy escasos los personajes aficionados a la literatura. De entre todos destaca uno: Robín Lebozán Castro de Cela. Robín es el más reflexivo y culto. Se nos presenta como sobrino-nieto del escritor Curros Enríquez (poeta liberal y anticlerical que contribuyó al renacimiento de la poesía gallega contemporánea). Posee libros, tiene buena memoria y muchas lecturas; cita a Edgar A. Poe, Antonio Machado y otros; gusta del Quijote y de los Episodios Nacionales de Galdós; tiene sus teorías sobre Bécquer y Rosalía; como gallego, gusta de la literatura gallega en general y de los escritores gallegos en particular; y detesta la quema de libros que hacen los vencedores. Es un personaje concienciado, critica abiertamente la guerra civil española y sus preferencias literarias van por escritores denunciadores de lo social. Pero lo más importante es que practica también la literatura. Cultiva la poesía en lengua vernácula, aunque no le gusta darla a conocer a los demás:

«Robín Lebozán escribe poesías en gallego, lo que no quiere es enseñarlas a la gente.

-No, a mí me parece que es un acto de impudor eso de leer a los demás las propias poesías, ¿a quién puede importarle?» (p. 230).

Pero lo más importante es que interviene como escritor de parte de esta «verdadera historia»:

«El carallo de Crego de Comesaña puede que sea tan orgulloso como el cura de San Miguel de Buciños, que ya saldrá en esta verdadera historia cuando le toque su tiempo» (p. 15).

Verdadera historia que es Mazurca para dos muertos, dentro de lo que toda ficción comporta. Son varios los testimonios que avalan nuestra afirmación:

«Cuando Robín Lebozán terminó de escribir lo que antecede, lo leyó en voz alta y se levantó» (p. 43).

«Robín se sienta en la mecedora y lee en voz alta todo lo que antecede... 
Robín Lebozán no quiere escribir un diario porque tampoco quiere reconocer que el hombre es bestia muy hirsuta y gregaria, muy aburrida y aficionada a advenimientos y milagros...» (pp. 121-122).

«Robín Lebozán se pasó toda la noche escribiendo, se siente como destemplado y se prepara café en un infiernillo de alcohol, no tiene más que prender la mecha, por lo menos el café estará caliente, entre sorbo y sorbo Robín Lebozán lee lo que ya va escrito y entorna los ojos para pensar...

- ¿Por qué no te acostaste en la cama?

-Ya lo ves, me pasé la noche escribiendo, voy a echarme ahora porque si no estaré cansadísimo todo el día» (pp. 189-190).

«Robín Lebozán, cuando se despierta por la noche, se alumbra con un quinqué, la luz eléctrica parece un vagalume tísico y sin fuerza, no vale para nada. Robín Lebozán lee lo que lleva escrito y corrige alguna que otra cacofonía o repetición o palabra poco clara y precisa, también cambia alguún signo ortográfico, aquí va mejor coma que dos puntos, aquí no pega un paréntesis, etc. Robín Lebozán piensa que todo va ya por la cuesta abajo, esto de las novelas es como la vida misma, se sube el corazón a la boca y la vida muere, escapa por los ojos y por la boca, también por la boca, las historias terminan siempre en un punto, en cuanto mate al hijoputa ya está, acuérdate otra vez de Poe, nuestros pensamientos eran lentos y marchitos, nuestros recuerdos eran traidores y marchitos...» (p. 233).

«Robín Lebozán vuelve sobre lo escrito, se sabe de memoria párrafos enteros y recuerda hastas las tachaduras, Lázaro Codesal fue el primer muerto de esta verdadera historia (p. 245).

Literatura dentro de la literatura, novela dentro de la novela, gracias a los diversos puntos de vista y los diferentes narradores que afloran en el relato de Cela. Así como en La familia de Pascual Duarte las fingidas memorias de Pascual Duarte constituyen el eje central de la novela más los relatos del transcriptor, en Mazurca para dos muertos el eje central es la escritura de esta historia por Robín Lebozán, siguiendo con la técnica de Cela de experimentar en cada novela nuevas estructuras y estilo ${ }^{4}$. Pero lo que interesa a nuestro propósito es que Robín Lebozán es, además de un lector consumado de literatura, un creador literario que evoca y plasma sus recuerdos y vivencias. ¿El personaje no es, en ocasiones, un trasunto de su creador?

Podemos afirmar que dentro de la sarta numerosa de personajes de Mazurca para dos muertos son pocos los aficionados a la literatura y que los gustos literarios sirven para pintar mejor los caracteres de sus

4 Cela, en las declaraciones a M. Friedrich aparecidas en el País Senanal, núm. 323, domingo 19 de junio de 1983 , pág. 25 , al preguntarle si tenía previsto un cambio de técnica en esta novela, afirmaba: «Probablemente sí, pero eso no es deliberado, es natural. Ya me he dado cuenta, por ejemplo, de que a veces se narra en tercera persona, y a veces en primera, y en algunas ocasiones también interrumpe el narrador en la acción, que, o bien es un hombre, o bien es una mujer». 
personalidades. Predominan los escritores y obras que el régimen franquista en su inicio no veía con buenos ojos, tanto por galleguistas como por ideas, no están ausentes los románticos y no faltan los siempre preferidos de Camilo José Cela: Cervantes, Quevedo, Rosalía de Castro ${ }^{5}$, además de Valle-Inclán, Baroja...

El tercer nivel de aproximación a nuestro tema es sobre la guerra civil española como hemos apuntado más arriba.

Sabemos que Camilo José Cela ha dedicado varias novelas al tema de la guerra civil. Dicho tema ocupa un lugar importante en la segunda mitad de Mazurca para dos muertos, con dos objetivos: primero, dar pie a una literatura más conceptual que textual; y segundo, puede permitir una crítica más atenta a las propuestas ideológicas que a su formación literaria.

La alusión a la guerra civil tendría así un doble sentido: primero, permite potenciar el asesinato de un miembro del clan de los Guxindes; y segundo, permite obligar a la reflexión y a la toma de decisiones respecto a sus propias vidas al terceto de primos protagonistas de la novela (Robín Lebozán, Raimundo el de los Casandulfles y el joven Camilo). Se trata aquí de un terreno propio para que el autor ponga de manifiesto su pensamiento. Por supuesto, se trataría de un pensamiento indirecto filtrado por algunas veces narrativas. En este sentido, en Mazurca para dos muertos, debe señalarse la coincidencia de la casi total mayoría de puntos de vista que reflexionan en torno al tema de la guerra civil, al considerarla una sangrienta locura y un disparate trágico:

\begin{abstract}
«Las matanzas están organizadas para la desilusión y el remordimiento y, a menos remordimiento, más desilusión, es lo de siempre, repásese la historia desde el imperio romano hasta nuestros días, las matanzas no arreglan nada y estropean muchas cosas durante mucho tiempo, a veces estrangulan dos generaciones o más y siembran el odio por donde pasan» (p. 127).

«-Yo creo que las mujeres tendrían que ir a las guerras, sería la forma de acabar con las guerras, las mujeres están más con los pies en el suelo que los hombres, tienen más sentido común, son más listas y prácticas y pronto verían que las guerras son un disaparate en el que se pierde todo: la razón, la salud, la paciencia, los ahorros y hasta la vida, en las guerras todos pierden algo y nadie gana nada, ni siquiera el que gana la guerra» (p. 131).
\end{abstract}

5 En la entrevista anteriormente citada se nombra a los tres escritores: de Cervantes y el Quijote se dice que a veces ha sido mal leído por algunos críticos; de Quevedo, que «es el más grande escritor que han visto los siglos jamás»; y de Rosalía, junto a Concepción Arenal y la condesa de Pardo Bazán, que «no es casualidad que las tres más importantes mujeres del siglo hayan sido gallegas», porque «la mujer gallega es la más importante de España y quizás del occidente europeo». 
«... puede que sea noble pelear por el territorio con los extranjeros, ipero un pensamiento que a lo mejor es mentira y entre españoles! Esto es cosa de locos» (p. 161).

«... Yo pienso que dentro de cincuenta años la gente todavía andará dándole vueltas a esta locura, esto es una locura y con todos estos farsantes heroicos y religiosos y políticos hay que andarse con cuidado porque no las piensan..." (p. 186).

La presencia de la guerra civil plantea también como lo anunciamos más arriba, la necesidad de una toma de decisiones para el terceto de primos protagonistas de la novela. Así Raimundo el de los Casandulfes toma la decisión de partir voluntario a una bandera legionaria. Coincidirá en sus razones con sus otros dos primos, Robín Lebozán y el joven Camilo:

«-Meterte en Portugal sería un error por los guardias, ya sabes, pero salir de aquí te es fácil, puedes apuntarte en la Bandera Legionaria Gallega de Barja Quiroga, yo creo que siempre será mejor la guerra que esto» (p. 152).

«El frente es menos criminal, no se puede decir pero allí no se asesina, hay menos veneno, también hay veneno, sí, pero no es tan descarado..." (p. 170).

Así, cuando el gobernador militar de la provincia llama a Raimundo el de los Casandulfes para nombrarle alcalde de Piñor de Cea, cargo que supone su complicidad moral con los escuadrones, el muchacho ya ha decidido el curso de su inmediato futuro:

«Me honra usted, mi teniente coronel, pero yo tenía pensado alistarme en la bandera Gallega, estaba a punto de salir de La Coruña.

-Bien, su conducta es digna de encomio, ¿podría usted darme algún nombre de confianza para ese cargo?

—No, señor, así de pronto no se me ocurre nadie» (pp. 152-153).

Por otra parte, Robín Lebozán y el joven Camilo esperan a que su quinta sea llamada a filas, lo que no tarda en suceder. El joven Camilo pronto se convertirá en "Camilo el artillero», mientras que su primo Robín Lebozán Castro de Cela, el novelista, la conciencia más reflexiva del terceto, es declarado inútil para el servicio: 
«Lista de mozos excluidos totalmente del servicio militar...: Robín Lebozán Castro de Cela fue clasificado apto para servicios auxiliares pero no lo mandaron llamar» (pp. 172-173).

¿No es esto lo que le ocurrió al joven Camilo José Cela? Sabemos que en 1936, la guerra civil española le sorprende con veinte años cumplidos. Estuvo en Madrid una temporada (unos catorce meses) y luego pasó a la zona nacionalista, el 5 de octubre de 1937. Conoció, por lo tanto, directamente la experiencia de los dos bandos en lucha.

A partir de estos ejemplos, podemos observar una fusión significativa de biografía y ficción que Camilo José Cela ha realizado desdoblándose a sí mismo en el terceto de personajes centrales de la novela.

Por fin, la novela nos da a conocer la toma de postura adoptada por Camilo José Cela en 1983 ante la guerra civil y la retaguardia que, obviamente, no coincide con la adoptada en 1936. De la novela, destacan algunos puntos: se nota una condena de la masacre de las dos Españas (nacional y republicana):

«-Yo estoy tan triste como tú, Monchiña, y muy asustado. Esto es horrible pero si la guerra se torciese para los nacionales iba a ser peor todavía, no me preguntes por qué, no sabría decírtelo, bueno, no quiero decírtelo» (p. 171).

Se nota también una crítica abierta de todos los mecanismos instaurados por los vencedores: la represión política, los tribunales militares, los mandatos del Boletín Oficial del Estado... De los textos siguientes, se puede extraer una lectura histórica de la postguerra:

«Es peor el Boletín Oficial que la guerra misma, no se puede decir pero es una verdad como un templo, ni lo dude, el Boletín Oficial es el arma de los meapilas, esos van a ser los grandes victoriosos, los vencedores para cincuenta años o más, tiempo al tiempo...» (pp. 189-190).

Por fin, se nota la denuncia del trágico retroceso que ha de dar la sociedad española:

«-Aquí, va a haber muchos crímenes, ya los está habiendo, y mucha estupidez, pero lo peor va a ser la marcha atrás que vamos a dar todos y que va a dar el país, ¡pobre España!, lo peor de estos estallidos es el triunfo de la vulgaridad, hay momentos en que el hombre se siente orgulloso de su vulgaridad y presume de burro y de ignorante, son los tiempos peores y también los más dramáticos y sangrientos...» (p. 154). 
A modo de conclusión, en cuanto al tema de la guerra, podemos afirmar que Camilo José Cela condena las guerras en general, y sobre todo, las guerras civiles españolas en particular:

«... puede que no sea noble pelear por el territorio con los extranjeros; ipero por un pensamiento que a lo mejor es mentira y entre españoles! Esto es cosa de locos» (p. 161).

Como podemos comprobar, Camilo José Cela distingue entre guerras entre países y guerras civiles, distingue asimismo entre los que luchan en el frente y los burócratas y tacha al administrativo de «cobarde escalafonario». También a los cobardes los llama «emboscados» y «pálidos» y dice que son los más peligrosos. Fabián Minguela, el asesino que mató a traición es cobarde, por lo tanto «pálido».

En su recorrido por la historia, Camilo José Cela ha encontrado el punto en que crecen en España la violencia y la intolerancia, ese momento comienza en el reinado de los Reyes Católicos y culmina en la guerra civil; en este recorrido por la historia y por la geografía de Galicia, reencuentra a sus escritores reseñados anteriormente, ValleInclán, Curros Enríquez, Rosalía de Castro... y sus leyendas, gallegas, bretonas, moras... con el fin de escribir una novela total, resumen de otras anteriores, que es a la vez, saga, retablo y crónica.

A lo largo de nuestro trabajo hemos visto cómo Camilo José Cela ha ido mezclando biografía y ficción en Mazurca para dos muertos, además del paralelismo existente entre los personajes de ficción y el autor, hemos notado cómo Camilo José Cela ha ido dejando distanciadamente y de una manera indirecta, huellas de su trayectoria vital, exponiendo su existencia desencantada en sus actividades profesionales, sociales y culturales (de allí los datos biográficos señalados, su participación en la guerra civil, desdoblándose asimismo en el terceto de primos protagonistas de la novela, su afición a la literatura...).

Teniendo en cuenta todos estos aspectos, podríamos afirmar que Mazurca para dos muertos sería un relato autobiográfico de ficción en la medida que reúne algunos de los elementos definidos por José Romera (1981: 27) entre otros, y que acabamos de señalar, en su estudio ya mencionado. Cuadraría así con la definición de Philippe Lejeune: 
«J'appellerai ainsi tous les textes de fiction dans les quels le lecteur peut avoir des raisons de soupçonner, à partir des ressemblances qu'ilt croit deviner, qu'il y a identité de l'auteur et du personnage, alors que l'auteur, lui, a choisi de nier cette identité, ou du moins de ne pas l'affirmer».

En Mazurca para dos muertos se perfilaría, por lo tanto, un intento de reconstrucción autobiográfica e histórica.

NOTA: Camilo José Cela: Mazurca para dos muertos. Barcelona: Seix Barral, 1980. Todas nuestras citas se refieren a esta edición.

\section{Referencias bibliográficas}

LeJEUnE, PH. (1975). Le pacte autobiographique. París: Seuil.

LÓPEZ, F. (1986). «Encuentro con Camilo José Cela». En Mazurca para Camilo José Cela. Madrid: Ayuntamiento de Palma y Ayuntamiento de La Coruña.

ROMERA CASTillo, J. (1981). «La literatura, signo autobiográfico». En La literatura como signo, J. Romera Castillo (ed.), 13-56. Madrid: Playor.

- (1984): «Presencia de la literatura en Mazurca para dos muertos, de Camilo José Cela». Epos 1, 241-260. 